\title{
Section Chemistry and the Environment
}

\section{A CHIMIA Column}

\section{The Swiss Chemical Society Establishes a New Section on 'Chemistry and the Environment' (SCE)}

On April 11, 2019, during the general assembly of the Division of Analytical Sciences, the establishment of a new 'Section on Chemistry and the Environment' (SCE) was announced. Here, I will briefly introduce the background against which this section was established, outline its institutional setting, and describe the short- and long-term vision of SCE.

\section{Chemicals and the Environment}

The interaction of natural and man-made chemicals with the bioand anthroposphere shapes our current life on earth. However, as a consequence of human activities, excessive amounts of chemicals accumulate in certain parts of the environment where they may negatively impact human and ecosystem health, both at the local and global level. Examples range from the eutrophication of surface waters to stratospheric ozone depletion.

\section{Why a 'Section on Chemistry and the Environment' in SCS?}

In Switzerland, the topic of 'Chemistry and the Environment' is highly relevant on at least three levels: First, Switzerland is home to some of the leading chemical industries, developing and producing a wide range of commodity chemicals, agrochemicals, and pharmaceuticals. The products of these companies generate an important economic and social benefit, but they may also impact the environment during manufacturing, use and disposal. Second, Swiss universities and research institutes have strong research and teaching programs in environmental chemistry, (eco-)toxicology and biogeochemistry, with many internationally leading experts in those fields. Third, the Swiss environmental authorities, both at the cantonal and federal level, are internationally renowned for introducing highly innovative environmental protection measures, e.g. (advanced) wastewater treatment, and for running some of the most dense and long-term aquatic and atmospheric monitoring networks.

While there is a long-standing and successful history of exchange and collaboration on these topics between Swiss authorities and research institutes, such liaisons are less established with the chemical industry. What is more, Swiss research groups have generally excellent international connections, while exchange at the national level may lag behind. It is against this background that the Swiss Chemical Society established the new 'Section on Chemistry and the Environment' (SCE).

\section{Institutional Setting and Structure of SCE}

SCE has been established as a section within the Division of Analytical Sciences (DAS). It is led by a board of eight members: Kathrin Fenner (Eawag \& University of Zurich, lead), Lukas Emmenegger (Empa), Jutta Hellstern (Novartis), Stefan Hoeger (IES Ltd), Tamar Kohn (EPFL), Heike Laue (Givaudan), Vera Slaveykova (University of Geneva), and Imelda Stamp (Syngenta). Board members represent academic and industrial research in different areas of Switzerland, from different sizes of institutions and companies, and a diversity of topics within the scope of SCE. The board is open to other interest groups, such as Swiss environmental authorities. At the European level, Thomas
Bucheli (Agroscope) represents SCS/SCE in the Division of Chemistry and the Environment of the European Chemical Society.

\section{Scope and Goals of SCE}

The scope of SCE comprises all activities related to "understanding and managing the chemical processes that molecules undergo in the environment". This allows fostering interdisciplinary exchange and to become home to a wide range of persons active in environmental research in Switzerland. Chemical processes occur all throughout the biosphere, i.e. in the terrestrial, aquatic and atmospheric environment, but also in anthroposphere. Therefore, all of these compartments are within the scope of the Section.

The major goals of the Section are to leverage high quality environmental chemistry \& (eco-)toxicology research in Switzerland, to generate innovative research ideas between academia, regulatory bodies and chemical industry, and to act as platform and network opportunity for young environmental chemists and (eco-)toxicologists.

\section{Activities of SCE}

SCE has already defined a number of short- and long-term activities. On April 3, 2020, the SCS Spring Meeting will be dedicated to 'Chemistry and the Environment', and will take place at the new campus of the FHNW in Muttenz. Six high-profile speakers will cover topics such as ozone chemistry, effect assessment of nanoparticles and microplastic, plastic biodegradation, benignby-design initiatives, and water quality protection. Also in spring 2020, a special topic issue of CHIMIA will present highlights from Swiss research on 'Chemistry and the Environment'. Contributions are still welcome, contact K. Fenner.

In the long-term, activities will include an annual or biannual scientific meeting to foster exchange within Switzerland, and roundtables on specific topics of interest (e.g. benign-by-design, in vitro methods, overarching sustainability approaches, environmental risk assessment, etc.). For the scientific meeting, we are exploring opportunities to stream contributions from relevant international conferences to reduce excessive travel of our members. On the educational side, we will organize industry visits and internships for students, and we will look into opportunities for joint teaching initiatives (e.g. MOOCs).

Interested in becoming a member of SCE? Please register at $s c g$. $\mathrm{ch} /$ membership and select our section during the registration process!

\section{Contact}

Prof. Dr. Kathrin Fenner

Eawag, Department of Environmental Chemistry

University of Zürich, Chemistry Department

Überlandstrasse 133

$\mathrm{CH}-8600$ Dübendorf

Switzerland

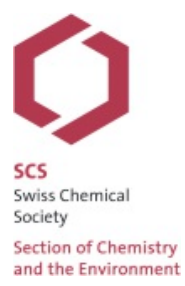

E-mail: kathrin.fenner@eawag.ch

scg.ch/sce 